\title{
Ação planejada e intenção empreendedora entre universitários: Analisando preditores e mediadores
}

\author{
Planned behavior and entrepreneurial intention among undergraduate \\ students: Analyzing predictors and mediators \\ Acciones planeadas e intención empresarial entre universitarios: Analizando \\ predictores y mediadores
}

\author{
Elisabeth LOIOLA ${ }^{1, a}$ \\ Sônia Maria Guedes GONDIMa \\ Cícero Roberto PEREIRA ${ }^{\mathrm{b}}$ \\ Aleciane Silva Moreira FERREIRA ${ }^{a}$ \\ Universidade Federal da Bahia, Salvador, BA, Brasil ${ }^{a}$, Universidade Federal da Paraíba, João Pessoa, PB, Brasil ${ }^{\natural}$
}

Resumo Este estudo analisa o efeito de variáveis de percepção de contexto do ambiente universitário e familiar e também de variáveis motivacionais e atitudinais na intenção empreendedora de jovens universitários. Testou-se também a influência indireta da atitude positiva em relação ao empreendedorismo nessas relações. Participaram 2.999 estudantes de diversos cursos de uma universidade pública do Brasil. Os resultados indicam que a motivação para o poder, seguida pela aprendizagem empreendedora e a menor percepção de risco são melhores preditores da intenção empreendedora. Além disso, os efeitos das relações entre motivos de poder, aprendizagem empreendedora e percepção de risco na intenção empreendedora são mediados pela atitude positiva em relação ao empreendedorismo. $\mathrm{O}$ estudo oferece evidências a favor das teorias da ação racional e da ação planejada, ressaltando o papel fundamental da atitude na intenção de escolha do empreendedorismo. Palavras-chave:

Intenção empreendedora; ação planejada; atitude; empreendedorismo.

\begin{abstract}
This study analyzes the effect of context perception variables in both academic and family environments, as well as motivational and attitudinal variables in the entrepreneurial intentions of university students. It also tested the indirect influence of positive attitude towards entrepreneurship among these relations. The participants in this study were 2,999 students from various departments at a public university in Brazil. The results indicate that the motivation for power, followed by entrepreneurial learning and lower perception of risk, are better predictors of entrepreneurial intention. In addition, the effects of the relationships between power, entrepreneurial learning, and perception of risk on entrepreneurial intention are mediated by positive attitude towards entrepreneurship. The study provides evidence for the theories of reasoned action and planned behavior, highlighting the key role of attitude in the intention to choose entrepreneurship.

Keywords:

Entrepreneurial intention; planned behavior; attitude; entrepreneurship
\end{abstract}

Resumen Este estudio analiza el efecto de las variables de percepción del contexto académico y familiar y también de las variables motivacionales y actitudinales sobre la intención empresarial de estudiantes universitarios. Ha sido puesta a prueba también la influencia indirecta de la actitud positiva hacia la carrera empresarial en estas relaciones. Participaron un total de 2.999 alumnos de varios cursos de una universidad pública de Brasil. Los resultados apuntan que la motivación por el poder, seguida del aprendizaje empresarial y la baja percepción de riesgo son los mejores predictores de la intención empresarial. Además, los efectos de las relaciones 
entre el poder, el aprendizaje empresarial y la percepción de riesgo sobre la intención empresarial son mediados por la actitud positiva hacia la carrera empresarial. El estudio presenta evidencias a favor de las teorias de la acción racional y planeada, destacando el papel fundamental de la actitud en la intención de elegir la carrera empresarial. Palabras-clave:

Intención empresarial; acción planeada; actitud; empresarial.

A

intenção empreendedora é definida como uma projeção pessoal de ações e metas futuras a serem implementadas para se desenvolver o próprio negócio (Fini, Grimaldi, Marzzochi, \& Sobrero, 2009). A pesquisa sobre o tema está fortemente embasada em duas grandes abordagens: a teoria do comportamento planejado, de Ajzen's (1991), e a teoria das oportunidades, de Shapero (1984; para uma revisão, ver Liñán \& Fayolle, 2015). Ambas as perspectivas assumem que a decisão de um jovem construir uma carreira empreendedora está relacionada a fatores de natureza contextual e também a aspectos motivacionais e atitudinais. Apesar de a literatura apontar a importância desses fatores, são raros os estudos que analisam o efeitos de fatores pessoais e contextuais simultaneamente.

Este artigo ajuda a preencher essa lacuna ao analisar em que medida cada um desses fatores contribui para a intenção de jovens universitários seguirem carreira empreendedora e como essa intenção é elaborada. Para responder a essas questões, testaram-se dois conjuntos de hipóteses inspiradas no modelo da ação planejada. Inicialmente identificaram-se os principais preditores da intenção empreendedora entre quatro variáveis de percepção de contexto (ambiente universitário, aprendizagem empreendedora, contato com disciplinas de empreendedorismo e envolvimento familiar) e duas variáveis motivacionais (motivos de escolha de carreira empreendedora e percepção de risco). Em seguida, analisou-se em que medida a atitude positiva em relação ao empreenderorismo representa o meio pelo qual a percepção de contexto e fatores motivacionais contribui para a intenção empreendedora.

A crença de que o empreendedorismo contribui para o desenvolvimento econômico e social tem levado estudiosos a investigarem mais detidamente o papel das variáveis de contexto na decisão de jovens de seguirem carreira empreendedora (p. ex., Sesen \& Pruett, 2014). A família, as redes sociais de trabalho (Abebe, 2012; Almeida \& Teixeira, 2014; Nanda \& S Sprensen, 2010), as ações empreendedoras de ex-colegas de curso universitário, principalmente homens (Kacperczyk, 2013), além da inclusão de cursos de empreendedorismo durante o período de formação universitária (p. ex., Franke \& Luthje 2004; Shinnar, Pruett, \& Toney, 2009; Wu \& $\mathrm{Wu}, 2008)$ predizem essa escolha. No entanto, os dados não são conclusivos, pois Packham, Jones, Miller, Pickernell e Brychan (2010) constataram que o impacto da educação empreendedora na decisão de seguir carreira nesse domínio varia conforme a cultura do país, o que converge com outros achados da literatura (p. ex., Kristiansen \& Indarti, 2004; Liñán, Urbana, \& Guerrero, 2011; Nascimento, Dantas, Santos, Veras, \& Costa Jr., 2010).

Variáveis individuais também têm sido exploradas. Traços pessoais, como lócus de controle interno e necessidade de realização, predizem intenção empreendedora (Nishantha, 2009; Santos, Minuzzi, Lezana, \& Grzyboyski, 2009). Além do lócus de controle interno, inovação, aceitação do risco e energia somam-se a outros traços pessoais do empreendedor (p. ex., Gurol \& Atsan, 2006; Thomas \& Mueller, 2000). Competências sociais, de gestão, psicológicas e motivações empreendedoras diferenciam o potencial empreendedor (CorreiaSantos, Caetano, \& Curral, 2010). Em revisão de cinco estudos de metanálises, Brandstätter (2011) concluiu que três fatores de personalidade impactam a intenção e o desempenho empreendedor: conscienciosidade, abertura à experiência e extroversão. Estudo de metanálise mais recente realizado por Frese e Gielnik (2014) reafirma o papel da autoeficácia, da busca de realização e da orientação empreendedora (proatividade) (p. ex., Parker, Bindl, \& Strauss, 2010), na criação e no sucesso do negócio.

Este estudo segue essa tendência de explorar o papel de variáveis individuais e de percepção de contexto na intenção empreendedora, fazendo uso da teoria da ação planejada. Converge com o estudo de Franklin (2013), ao buscar contribuir para o alargamento da compreensão das motivações na escolha de carreira empreendedora. Alinha-se ainda às recomendações de Frese e Gielnik (2014), na medida em que explora efeitos de mediação de atitudes, de percepção de controle e de normas subjetivas na relação entre variáveis preditivas, de corte contextual e individual, e a intenção de carreira empreendedora. Atende também à indicação de Bouckenooghe, Clercq, Willem e Buelens (2007) ao se valer de análise confirmatória, por meio de modelagem de equações estruturais para teste empírico das relações entre variáveis antecedentes, mediadoras e critério. 
Espera-se que os resultados contribuam para ajudar a elaboração de políticas universitárias que venham a criar um clima favorável ao empreendedorismo, subsidiando programas de capacitação de futuros empreendedores.

\section{Fatores explicativos do empreendedorismo}

Múltiplas explicações sobre o empreendedorismo têm sido propostas para se compreender porque algumas pessoas e não outras engajam-se em carreira empreendedora. Abordagens econômicas afirmam que o fenômeno se deve a motivações financeiras (p. ex., maiores lucros) e econômicas (p. ex., crescimento da empresa). A inovação, na perspectiva de Schumpeter (1949), responde por mudanças nos diversos ciclos econômicos e está intimamente ligada a ações empreendedoras. Aspectos subjetivos, como capacidade de inovar e lidar com a incerteza são igualmente relevantes. Ao inovar, o empreendedor incorpora novos conhecimentos a produtos, processos, mercados e organizações. Sua percepção de maior controle dos resultados de suas ações o torna mais hábil a lidar com ambientes instáveis.

O empreendedorismo, na visão de Kirzner (1997), é um processo emergente que dinamiza os mercados, manifestando-se em três esferas: a do ator (empreendedor), a de suas descobertas e a da competição dinâmica. $\mathrm{O}$ ator é aquele que identifica oportunidades. As descobertas se referem a processos deflagrados pelo "alerta empreendedor", para detectar e corrigir erros prévios mediante ações responsivas, persistentes e criativas. A competição dinâmica é um jogo de forças que identifica lacunas de conhecimentos a serem preenchidas por ações empreendedoras.

A identificação de oportunidades torna-se central no empreendedorismo (Vaghely \& Julien, 2010). Acrescenta-se também a recombinação criativa de recursos (Shane, 2012). No entanto, evidências empíricas sugerem que tanto a necessidade (orientação para o passado) quanto as oportunidades (orientação para o futuro) respondem pelo empreendedorismo (Williams, Round, \& Rodgers, 2009), revelando a complexidade das motivações para empreender.

\section{Fatores motivacionais de carreira empreendedora}

A motivação é um processo psicológico básico ativado por necessidades, afetos, valores, metas e expectativas, que levam alguém a agir de modo persistente para alcançar objetivos (Gondim \& Silva, 2013). Embora se reconheça que a motivação atua no nível intrapsíquico, visto que é a pessoa que se move em direção a um objetivo, fatores externos e contextuais podem ativá-la. A cultura, por exemplo, pode ajudar na disseminação de valores de empreendedorismo (Almeida, 2013; Martin \& Picazo, 2009; Sesen \& Pruett, 2014). Estudos recentes têm se ocupado das motivações que levam jovens universitários a seguir carreira empreendedora e a montar o seu próprio negócio. Motivos econômicos e de realização pessoal encontram-se mesclados (Fé de Pinho \& Gaspar, 2012).

Ao analisarem estudos anteriores sobre motivação de carreira empreendedora e suas barreiras, Sesen e Pruett (2014) encontraram 38 obstáculos ao empreendedorismo. Desse total, 25 são relativos a fatores externos (mercado, falta de capital, de estímulos culturais e econômicos). Os 13 motivos internos relacionam-se a aspectos motivacionais (medo de assumir responsabilidades e riscos e do estresse), à falta de conhecimento, de autoconfiança e de competências básicas de gestão e, também, à ausência de redes sociais.

Especificamente com foco em intenção empreendedora, Sivarajah e Achchuthan (2013) analisaram estudos realizados na Ásia, África e Europa na perspectiva transcultural e concluiram que variáveis individuais desejo de se autoempregar, percepção de viabilidade do autoemprego, tolerância ao risco - e suporte percebido do ambiente são importantes preditores. De modo equivalente, Fatoki (2010) e Vale (2014) evidenciaram a importância do contexto nas motivações empreendedoras ao lado das características pessoais, incluindo criatividade e inovação.

Em estudo recente, Vale, Corrêa e Reis (2014) identificaram maior peso de fatores contextuais do que motivacionais no empreendedorismo. Dar continuidade ou ampliar os negócios da família, ter sido demitido e dispor de capital, e encontrar-se insatisfeito com o emprego são alguns deles. Outros estudos trazem evidências a favor de variáveis de contexto proximais, como ambiente familiar, a exemplo de ter pais empreendedores (p. ex., Geldhof, Weiner, Agans, Mueller, \& Lerner, 2014; Schoon \& Duckworth, 2012).

O ambiente universitário também aparece provendo condição favorável para o empreendedorismo. Estudo de Kacperczyk (2013) conclui que mais que a oferta de disciplinas relacionadas ao tema, o ambiente universitário oferece contribuições ao empreendedorismo pelo fortalecimento de relações entre ex-colegas egressos 
de curso universitário que iniciaram seus negócios e ao, serem bem-sucedidos, passaram a servir de exemplos positivos. O estudo de Nanda e S $\varphi$ rensen (2010) havia concluído que a experiência positiva de colegas de trabalho faz aumentar em 14\% a probabilidade de alguém se tornar empreendedor, e os resultados de Kacperczyk (2013) revelaram que o aumento é de $20 \%$ em caso da influência de ex-colegas de universidade. Participação em atividades extracurriculares, além de incentivos dados por agentes escolares, mostra-se associada ao desejo de vencer, à autorrealização e à criação do negócio (Rocha \& Freitas, 2014).

\section{Explicando as intenções comportamentais}

Há dois grandes modelos de predição da intenção de carreira empreendedora. O modelo de KruegerShapero (Krueger, 1993; Shapero \& Sokol, 1982) se baseia na crença do empreendedorismo como fator emergente e se sustenta em três componentes: o desejo (afeto) de se autoempregar, a viabilidade de que issto venha a ocorrer (análise de oportunidades) e a propensão para agir nessa direção (comportamento orientado para objetivos). O segundo modelo é o da ação planejada, derivado da teoria da ação racional ou refletida (p. ex., Ajzen, 2011; Armitage \& Conner, 2001; Engle et al., 2010; Robinson, Stimpson, Heufner, \& Hunt, 1991; Schlaegel \& Koenig, 2014).

As teorias da ação racional (Fishbein, 1963; Fishbein \& Ajzen, 1975) e da ação planejada (Ajzen, 1985) postulam que os seres humanos buscam e avaliam informações disponíveis para tomar decisões sobre suas ações e comportamentos. O esforço das duas teorias é no sentido de compreender os antecedentes individuais e contextuais (no nível perceptivo) que levariam cada pessoa a manifestar uma intenção comportamental. A suposição é a de haver forte relação entre intenção, disposição e comportamento futuro.

Para a teoria da ação racional, as atitudes (individuais) e as normas subjetivas (contexto) funcionariam como antecedentes da intenção comportamental, ao lado das crenças comportamentais, da avaliação das consequências do comportamento, das crenças normativas (pressão social) e da motivação. Atitudes se referem à avaliação afetiva que os indivíduos fazem de um objeto social que leva à atratividade ou distanciamento do objeto-alvo da atitude. Funcionam como preditores do comportamento, porque fazem o sujeito tender a exibir comportamentos congruentes com o afeto despertado pelo objeto (Albarracin, Johnson, Zanna, \& Kumkale, 2005; Pereira, 2015).

As teorias da ação racional e planejada (p. ex., Ajzen \& Fishbein, 2005), em contraponto, postulam que atitudes não são suficientes para predizer comportamentos, pois se distanciam dele. Variáveis proximais, a exemplo da intenção comportamental, cumprem papel de preditor mais relevante, embora se reconheça a discussão crítica acerca de qual seria a melhor forma de mensurar intenção comportamental (Moutinho \& Roazzi, 2010).

Além da atitude, as teorias da ação racional e da ação planejada incluem a norma subjetiva, que consiste na percepção da avaliação de grupos sociais de referência sobre o comportamento a ser adotado pelo indivíduo. As crenças comportamentais, em particular, se referem à força de opiniões a favor ou contra o comportamento almejado, que interage com a avaliação das consequências de um dado comportamento, vindo a influenciar as atitudes. Em resumo, crenças influenciam atitudes, que, por sua vez, impactam na intenção comportamental, que se presume ser o melhor preditor de comportamento futuro.

Três tipos de crenças repercutem na intenção comportamental: sobre o comportamento a adotar, sobre as normas (pressão social) e sobre o controle que se tem sobre o comportamento (Ajzen, 1985). A racionalidade, afinal, só se faz presente no nível consciente. Comportamentos decorrentes de processos automáticos ou inconscientes são menos suscetíveis à influência de motivos racionais.

A teoria da ação planejada avança um pouco mais no modelo de explicação da intenção comportamental ao incluir a percepção de controle do comportamento pelo ator (Ajzen, 2011; Heidemann, Araujo, \& Veit, 2011). Esse último conceito se aproxima da autoeficácia (Bandura, 1991), definida como a percepção de capacidade pessoal para realizar uma tarefa com êxito. Diversos trabalhos têm acumulado evidências de sua importância na predição da intenção empreendedora (p. ex., Akmaliah, Pihine, \& Bagheri, 2013; Mortan, Ripoll, Carvalho, \& Bernal, 2014).

No caso dos estudos de empreendedorismo, percepção de controle do comportamento se relaciona com o conceito de percepção de risco, definido por Pennings e Wansink (2004) como um processo cognitivo de identificação, armazenagem e recuperação de informações relacionadas à criação do negócio. A avaliação de riscos de insucesso acompanha, portanto, a decisão de abrir um negócio em função de maior ou menor controle 
sobre variáveis de individuais (capacidades) e contextuais (concorrência, estudos prospectivos de tendências de mercado, grau de necessidade de investimento, etc). A capacidade de correr riscos de forma calculada e improvisar (Frese \& Gielnki, 2014) exerce papel importante no ato de empreender.

\section{MÉTODO}

\section{Participantes}

Participaram 2.999 estudantes de diversos cursos de uma universidade pública de ensino superior do nordeste do Brasil, sendo 18\% dos cursos de medicina e ciências da saúde, 16\% de engenharia e arquitetura, 10\% de ciências sociais, $6 \%$ de direito, $5 \%$ de artes, $5 \%$ de administração e negócios e $40 \%$ não especificaram. A idade média foi de 25 anos $(D P=6,11)$ e $40,2 \%$ do sexo masculino. Do total, 31\% qualificam seu desempenho acadêmico como bem acima da média, $35 \%$ como acima da média e $27,4 \%$ como na média. Com relação ao estado civil, $73,2 \%$ são solteiros, $24,2 \%$, casados ou vivem juntos e $2,5 \%$, divorciados. Nunca tiveram contato com disciplinas de empreendedorismo, $77 \%$, e $23 \%$ fizeram ao menos uma disciplina. Dos participantes, $40 \%$ possuem ao menos um dos pais ou algum outro membro da família exercendo atividades empreendedoras, enquanto $32 \%$ afirmaram que nenhum dos pais possui o próprio negócio. Da amostra, $47 \%$ trabalham, em média, 31,98 horas por semana $(D P=12,11)$.

\section{Instrumento}

O instrumento original do Global University Entrepreneurial Spirit Students' Survey (GUESSS) tem 12 blocos de questões: (a) dados pessoais; (b) perfil do estudante (área de formação, curso, etc.); (c) intenções de escolha de carreira (ser seu próprio patrão, ser empregado, suceder negócios da família); (d) motivos de escolha de carreira (poder e realização); (e) instituição de ensino (ambiente geral de aprendizagem e aprendizagem empreendedora específica); (f) perfil empreendedor do estudante; (g) experiências familiares; (h) características do processo de socialização no país; (i) planejamento do negócio (motivações, metas, etc.); (j) informações gerais sobre o negócio (filtro - quando for o caso); ( $\mathrm{k}$ ) informações sobre negócios da família (filtro - quando for o caso); (1) questões específicas de cada país onde é aplicado o estudo (p. ex., educação dos pais, renda familiar, características pessoais do estudante).

Para fins de análise deste estudo foram selecionadas 37 questões. O contexto proximal e distal é apreendido por questões sobre o ambiente universitário favorável ao empreendedorismo (p. ex., disciplinas e processo de socialização), ambiente familiar (pais empreendedores), ambiente social imediato (norma subjetiva) e, em nível individual, as questões abrangem motivações para empreender (poder, realização pessoal), percepção de controle e de risco, atitude empreendedora e intenção de seguir carreira empreendedora (Tabela 1).

O instrumento faz parte do GUESSS (http://www.guesssurvey.org/) $)^{2}$, uma pesquisa internacional que, em 2013/2014, alcançou 34 países, incluindo o Brasil. O objetivo é acompanhar indicadores perceptivos de variáveis de nível individual e contextual do ambiente universitário relacionados ao empreendedorismo entre estudantes de nível superior.

TABELA1. Especificações do instrumento

\begin{tabular}{|c|c|c|c|}
\hline Variáveis & Itens & Tipo de escala & $\begin{array}{c}\text { Alfa de } \\
\text { Cronbach }\end{array}$ \\
\hline \multicolumn{4}{|c|}{ Contextuais distais } \\
\hline Ambiente universitário & $\begin{array}{l}\text { Três itens sobre atmosfera e clima universitário favorável } \\
\text { ao empreendedorismo }\end{array}$ & $\begin{array}{l}\text { Likert* } \\
\text { de } 1 \text { a } 7\end{array}$ & 0,90 \\
\hline Aprendizagem empreendedora & $\begin{array}{l}\text { Três itens de aperfeiçoamento de habilidades para iden- } \\
\text { tificar oportunidades, iniciar o negócio e desenvolver re- } \\
\text { des de relações a partir de disciplinas cursadas (p. ex., } \\
\text { as disciplinas e atividades que eu fiz aperfeiçoaram mi- } \\
\text { nhas habilidades de gestão para iniciar um negócio) }\end{array}$ & $\begin{array}{l}\text { Likert* } \\
\text { de } 1 \text { a } 7\end{array}$ & 0,86 \\
\hline
\end{tabular}


Contato com disciplinas de empreendedorismo

Experiência familiar

Norma subjetiva

Motivos engajamento carreira
empreendedora

empreendedora

Percepção de risco

Controle percebido

Atitude empreendedora

Intenções escolha de carreira
Uma questão sobre intensidade de contato com disciplinas em empreendedorismo

Uma questão sobre experiência paterna e materna em empreendedorismo

Três itens sobre apoio social de pais, irmãos, amigos e colegas à decisão de ser empreendedor (p. ex., se eu fosse seguir a carreira empreendedora, tendo meu próprio negócio, como estas pessoas reagiriam)

\section{Escore de 1 a 3}

Escore de 1 a 3

Likert*

de 1 a 7

0,86

Individuais
Cinco itens sobre motivos de poder (p. ex., ter poder para tomar decisões, ser meu próprio patrão), de criatividade e de realização pessoal na escolha da carreira empreendedora (p. ex., realizar o sonho; criar algo)

Três itens sobre nível de consciência do risco de abrir o próprio negócio (p. ex., acho perigoso administrar meu próprio negócio)

Quatro itens sobre percepção, controle e carreira empreendedora (p. ex., como meu próprio patrão eu teria total controle da situação)

Cinco itens sobre nível de identificação pessoal com a abertura do próprio negócio. (p. ex., uma carreira empreendedora é algo atraente para mim).

Seis itens sobre o quanto a carreira de empreendedor (abrir seu próprio negócio) está nos projetos de vida dos universitários (p. ex., minha meta profissional é tornar-me empreendedor(a), estou determinado(a) a criar uma empresa no futuro).

$\begin{array}{cc}\begin{array}{c}\text { Likert de } 1 \\ \text { a } 7^{*}\end{array} & \begin{array}{c}\text { Poder } \\ 0,75 \\ \text { Realização } \\ 072\end{array} \\ \begin{array}{c}\text { Likert* } \\ \text { de 1 a } 7\end{array} & 0,87 \\ \begin{array}{c}\text { Likert* } \\ \text { de 1 a 7 }\end{array} & 0,90 \\ \begin{array}{c}\text { Likert* } \\ \text { de 1 a } 7\end{array} & 0,91 \\ \text { Likert* } & \\ \text { de 1 a } 7 & 0,94\end{array}$

Nota. *Resposta Likert 1 - discordo completamente (nada importante ou nada, conforme o item) e 7 -concordo completamente (muito importante, muito, conforme o item).

\section{Procedimentos de coleta de dados}

Receberam por e-mail um convite para participar do estudo 23 mil alunos matriculados em uma instituição federal de ensino superior do nordeste do Brasil. Os e-mails foram enviados pelo setor de Tecnologia de Informação da referida instituição, tendo sido reiterado o convite em dois outros momentos. Em respeito aos princípios éticos, a adesão à pesquisa era voluntária, tendo a Instituição de Ensino Superior (IES) apenas apoiado a iniciativa. A coleta ocorreu no final de 2012.

\section{Procedimentos de análise de dados}

Utilizou-se o Statistical Package for Social Science, versão 19 (SPSS) para os procedimentos de análise dos pressupostos de normalidade da distribuição dos resíduos, não tendo sido encontrados valores atípicos univariados e multivariados (distância quadrada de Mahalanobis $\left.-D^{2}, p<0,01\right)$. Os coeficientes de assimetria $(S k)$ e curtose $(K u)$ mantiveram-se dentro dos limites esperados para distribuição normal dos resíduos (Fields, 2009; Marôco, 2010). Os resultados são apresentados em termos de medidas de tendência central $(M)$ e desviopadrão $(D P)$. Para avaliar a força das relações entre as variáveis do modelo, análises de regressões multivariadas foram usadas para testar os efeitos dos preditores e dos mediadores na intenção empreendedora.

Usou-se também Modelos de Equações Estruturais com variáveis latentes (MEE; AMOS 19 - Analysis of Moment Structures; Arbuckle, 2010) com o objetivo de testar um modelo de mediação proposto (Marôco, 2010). O Maximum Likelihood (ML) foi o método de estimação escolhido. Os indicadores de ajustamento dos modelos foram: $\chi^{2}$ (valores menores, $\left.p>0,05\right), \chi^{2} / g l$, valores até 2 (Byrne, 2001); CFI (Comparative Fit Index) é um índice comparativo, valor de referência igual ou acima de 0,90; RMSEA (Root Mean Square Error of Approximation), com melhores ajustes para valores próximos a 0,06 e 0,08; AIC (Akaike Information Criterion), índice que não possui valores de referências servindo para comparação de modelos, sendo os menores valores os que oferecem melhor ajuste; PCFI (Parsimony Comparative Fit Index), valor de referência > 0,80. 


\section{RESULTADOS}

\section{Análises preliminares}

A Tabela 2 mostra as associações entre todas as variáveis do estudo com a intenção empreendedora. Em relação aos principais componentes da teoria da ação planejada, a atitude apresenta maior associação $(r=0,837$; $p<0,01)$, seguida do controle percebido e da norma subjetiva. No entanto, a média de normas subjetivas é maior que as demais. Entre as variáveis do contexto universitário, a associação mais forte aparece com a aprendizagem empreendedora, seguida do ambiente universitário e do contato com disciplinas sobre o tema. $\mathrm{O}$ envolvimento familiar apresenta-se fracamente associado à intenção empreendedora $(r=-0,045 ; p<0,05)$. Entre os motivos, o de poder apresenta mais forte associação com intenção empreendedora que os de realização. A percepção de risco relaciona-se negativamente com a intenção empreendedora $(r=-0,138 ; p<0,01)$.

TABELA 2. Correlações entre as variáveis do estudo incluindo média e desvio padrão

\begin{tabular}{|c|c|c|c|c|c|c|c|c|c|c|c|c|}
\hline Var & 1 & 2 & 3 & 4 & 5 & 6 & 7 & 8 & 9 & 10 & 11 & \\
\hline 1. & - & $\begin{array}{c}3,80 \\
(D P=1,82)\end{array}$ & & & & & & & & & & \\
\hline 2. & 0,20 "* & - & $\begin{array}{c}3,84 \\
(D P=1,68)\end{array}$ & & & & & & & & & \\
\hline 3. & $0,30^{* *}$ & $0,64^{* *}$ & - & $\begin{array}{c}4,04 \\
(D P=1,61)\end{array}$ & & & & & & & & \\
\hline 4. & $0,14^{\prime \prime}$ & $0,13^{* *}$ & $0,24^{* *}$ & - & $\begin{array}{c}1,43 \\
(D P=0,95)\end{array}$ & & & & & & & \\
\hline 5. & $0,04^{*}$ & $-0,03$ & $-0,02$ & 0,03 & - & $\begin{array}{c}1,47 \\
(D P=0,57)\end{array}$ & & & & & & \\
\hline 6. & $0,44^{*}$ & $0,17^{* *}$ & $0,19^{* *}$ & $0,06^{* *}$ & 0,03 & - & $\begin{array}{c}5,54 \\
(D P=1,05)\end{array}$ & & & & & \\
\hline 7. & $0,29^{* *}$ & $0,24^{* *}$ & $0,22 *$ & 0,01 & $-0,02$ & $0,46^{* *}$ & - & $\begin{array}{c}5,94 \\
(D P=0,94)\end{array}$ & & & & \\
\hline 8. & $0,14^{\prime \prime}$ & $-0,04^{*}$ & $-0,06^{* *}$ & $-0,01$ & $-0,02$ & $-0,06^{* *}$ & $-0,06^{* *}$ & - & $\begin{array}{c}4,30 \\
(D P=1,55)\end{array}$ & & & \\
\hline 9. & 0,84 & $0,16^{* *}$ & $0,25^{* *}$ & $0,12^{* *}$ & 0,03 & $0,42^{* *}$ & $0,26^{* *}$ & $-0,13^{* *}$ & - & $\begin{array}{c}4,52 \\
(D P=1,81)\end{array}$ & & \\
\hline 10. & $0,50^{* *}$ & $0,19^{* *}$ & $0,25^{* *}$ & $0,07^{* *}$ & $0,06^{* *}$ & $0,36^{* *}$ & $0,24^{* *}$ & $-0,19^{* *}$ & $0,51^{* *}$ & - & $\begin{array}{c}4,19 \\
(D P=1,55)\end{array}$ & \\
\hline 11. & $0,34^{* *}$ & $0,15^{*}$ & $0,15^{* *}$ & $0,04^{*}$ & $0,05^{* *}$ & $0,26^{* *}$ & $0,19^{* *}$ & $-0,11^{*}$ & $0,39^{* *}$ & $0,36^{* *}$ & - & $\begin{array}{c}5,90 \\
(D P=1,18)\end{array}$ \\
\hline
\end{tabular}

Nota. Significância de ** $p<0,001$; * $p<0,05$. 1-Intenção de carreira empreendedora; 2-Ambiente universitário; 3-Aprendizagem empreendedora; 4-Contato com disciplinas de empreendedorismo; 5-Envolvimento familiar com o empreendedorismo; 6-Motivação de poder; 7-Motivação de realização pessoal; 8-Percepção de risco; 9-Atitude empreendedora;10- Controle percebido; 11-Norma subjetiva. Os números na diagonal indicam a média e o desvio-padrão das variáveis.

\section{Preditores da intenção empreendedora}

A Tabela 3 apresenta os resultados das análises de regressão em que se analisa o impacto da percepção de contexto e de variáveis motivacionais na intenção empreendedora. As variáveis preditoras respondem por 26,3\% da variância da intenção empreendedora. Os coeficientes de regressão padronizados indicam que a variável motivos de poder exerce efeito substancial na intenção empreendedora $(\beta=0,361 ; p<0,001)$. Isto é, a busca pelo poder sobre os outros e pela liberdade para tomar decisões prediz a intenção empreendedora. A aprendizagem empreendedora, o contato anterior com o campo e os motivos de realização também fortalecem a intenção, mas com menor força. A percepção de risco é o único fator que inibe o empreendedorismo. 


\begin{tabular}{lccc}
\hline \multicolumn{1}{c}{ Preditoras } & \multicolumn{3}{c}{ Intenção empreendedora } \\
\cline { 2 - 4 } Constante & $\boldsymbol{B}$ & $\boldsymbol{S E}$ & $\beta$ \\
Ambiente universitário & 3,837 & 0,030 & $-0,021$ \\
Aprendizagem empreendedora & $-0,023$ & 0,023 & $0,193^{\star *}$ \\
Contato com empreendedorismo & 0,219 & 0,025 & $0,077^{\star *}$ \\
Envolvimento familiar & 0,148 & 0,033 & 0,035 \\
Motivo de poder & 0,111 & 0,053 & $\mathbf{0 , 3 6 1 ^ { \star * }}$ \\
Motivo de realização & 0,621 & 0,032 & $0,087^{\star *}$ \\
Percepção de risco & 0,167 & 0,036 & $-0,096^{\star *}$
\end{tabular}

Nota. $B$ = coeficiente de regressão não padronizado; $S E$ = Erro padrão; $\beta=$ Coeficiente de regressão padronizado. * $p<0,001 ;{ }^{*} p<0,05$. $R^{2}$ ajustado: 0,263 (N=2.999).

Estimou-se outro modelo de regressão com o objetivo de observar o papel das variáveis do estudo após se ter em conta os propagáveis mediadores do emprendedorismo. Ao incluir as variáveis mediadoras nas análises de regressão (Tabela 4), constatou-se que, juntas, as variáveis preditoras explicam $72 \%$ da variância da intenção empreendedora. Os coeficientes de regressão padronizados indicam que a atitude empreendedora se relaciona mais fortemente com a intenção empreendedora $(\beta=0,738 ; p<0,001)$. Quanto mais positiva é a atitude dos estudantes em relação ao empreendedorismo, mais forte é a sua intenção de seguir essa carreira. $\mathrm{O}$ controle percebido também exerce um efeito significativo, embora seja muito fraco em relação ao efeito da atitude. A norma subjetiva não exerce qualquer impacto direto na intenção. De maior importância, os efeitos das outras variáveis preditoras reduziram-se substancialmente, com especial destaque para os motivos de poder. Essa redução, após a inclusão da atitude, do controle percebido e da norma subjetiva, aponta claramente para a possibilidade de essas variáveis atuarem efetivamente como mediadoras do efeito de fatores contextuais e motivacionais na intenção empreendedora.

TABELA 4. Variáveis do estudo incluindo as mediadoras na intenção de carreira

\begin{tabular}{|c|c|c|c|}
\hline \multirow{2}{*}{ Preditoras } & \multicolumn{3}{|c|}{ Intenção empreendedora } \\
\hline & $B$ & $S E$ & $\beta$ \\
\hline Constante & 3,808 & 0,018 & \\
\hline Ambiente universitário & $-0,001$ & 0,014 & $-0,001$ \\
\hline Aprendizagem empreendedora & 0,075 & 0,015 & $0,066^{* *}$ \\
\hline Contato com empreendedorismo & 0,058 & 0,020 & $0,030^{*}$ \\
\hline Envolvimento familiar & 0,035 & 0,033 & 0,011 \\
\hline Motivo de poder & 0,132 & 0,021 & $0,076^{\star \star}$ \\
\hline Motivo de realização & 0,058 & 0,022 & $0,030^{*}$ \\
\hline Percepção de risco & $-0,020$ & 0,012 & $-0,017^{*}$ \\
\hline Atitude empreendedora & 0,743 & 0,013 & $0,738^{\star *}$ \\
\hline Controle percebido & 0,087 & 0,015 & $0,074^{\star *}$ \\
\hline Norma subjetiva & $-0,011$ & 0,017 & $-0,007$ \\
\hline
\end{tabular}

Nota. $B=$ coeficiente de regressão não padronizado; $S E=$ Erro padrão; $\beta=$ Coeficiente de regressão padronizado. ${ }^{* *} p<0,001 ;{ }^{*}$ $p<0,05 . R^{2}$ ajustado: 0,720 (N=2.999).

Para analisar a possibilidade de mediação, estimaram-se os efeitos dos preditores contextuais e motivacionais nas três variáveis mediadoras propostas. O modelo explica 37,2\% da variância das respostas de atitude empreendedora; 33,9\% do controle percebido e 18,8\% da norma subjetiva (Tabela 5). Os melhores preditores da atitude empreendedora são os motivos de poder e a aprendizagem empreendedora. Motivo de poder, aprendizagem empreendedora e envolvimento familiar são preditores do controle percebido. A percepção de risco prediz negativamente o controle percebido, ou seja, o aumento da percepção de risco está associado à diminuição do controle percebido. Motivo de poder e ambiente universitário predizem a norma subjetiva. A percepção de risco segue tendo efeito negativo sobre a norma subjetiva.

Os resultados obtidos pelas análises de regressão orientaram o teste do modelo de mediação da atitude nas relações entre as variáveis antecedentes (aprendizagem empreendedora, percepção de risco e motivo de poder) e a intenção empreendedora. A escolha da atitude empreendedora decorreu do fato de se mostrar como a melhor preditora da intenção empreendedora (ver Tabela 4). Embora a teoria da ação planejada reafirme a importância 
do controle percebido no aumento da intenção empreendedora, a forte correlação obtida entre atitude e intenção na amostra deste estudo fez com que a opção fosse testar o poder mediador da atitude. A percepção de risco foi incluída para controlar o seu efeito, por ter sido a única variável associada negativamente com intenção empreendedora, motivação de poder e aprendizagem empreendedora, e pelo resultado da primeira análise de regressão sem os mediadores, que reafirmou seu efeito redutor da intenção empreendedora.

\section{Modelo de mediação}

O teste do modelo de mediação inclui quatro variáveis latentes, cada uma medida por três itens mais representativos de cada conceito. As variáveis latentes do modelo são: aprendizagem empreendedora (disciplinas gerais que permitiam o desenvolvimento de competências empreendedoras), motivação pelo poder (desejo de abrir o negócio para ser autônomo e independente), percepção de risco (consciência dos riscos de abrir um negócio) e intenção empreendedora (desejo de abrir o seu proprio negócio).

TABELA 5. Variáveis do estudo sobre as variáveis mediadoras

\begin{tabular}{|c|c|c|c|c|c|c|c|c|c|}
\hline \multirow{2}{*}{ Preditoras } & \multicolumn{3}{|c|}{ Atitude empreendedora ${ }^{1}$} & \multicolumn{3}{|c|}{ Controle percebido ${ }^{2}$} & \multicolumn{3}{|c|}{ Norma subjetiva $^{3}$} \\
\hline & $B$ & $S E$ & $\beta$ & $B$ & $S E$ & $\beta$ & $B$ & $S E$ & $\beta$ \\
\hline Constante & 4,549 & 0,027 & - & 4,215 & 0,024 & - & 5,916 & 0,020 & - \\
\hline Amb. Univ. & $-0,061$ & 0,021 & $-0,056^{*}$ & 0,032 & 0,019 & 0,034 & 0,046 & 0,016 & $0,066^{*}$ \\
\hline Apr.Empr. & 0,114 & 0,023 & $0,102^{\star *}$ & 0,082 & 0,020 & $0,085^{\star \star}$ & $-0,012$ & 0,017 & $-0,016$ \\
\hline Contato & 0,121 & 0,030 & $0,063^{\star *}$ & $-0,025$ & 0,026 & $-0,015$ & $-0,022$ & 0,022 & $-0,018$ \\
\hline Env.Fami. & $-0,003$ & 0,049 & $-0,001$ & 0,103 & 0,043 & $0,038^{*}$ & 0,062 & 0,036 & 0,030 \\
\hline Mot.Poder & 0,383 & 0,031 & $0,224^{\star *}$ & 0,185 & 0,028 & $0,126^{\star \star}$ & 0,076 & 0,023 & $0,068^{*}$ \\
\hline Mot.Real. & 0,069 & 0,033 & 0,036 & 0,059 & 0,029 & $0,036^{*}$ & 0,046 & 0,025 & 0,037 \\
\hline Perc.Risco & $-0,022$ & 0,018 & $-0,018$ & $-0,120$ & 0,016 & $-0,120^{\star \star}$ & $-0,029$ & 0,013 & $-0,038^{*}$ \\
\hline
\end{tabular}

Nota. $B$ = coeficiente de regressão não padronizado; $S E$ = Erro padrão; $\beta=$ Coeficiente de regressão padronizado. ${ }^{* *} p<0,001 ;$ * $p<0,05 . R^{2}$ ajustado': 0,372 ( $\left.N=2.999\right) . R^{2}$ ajustado2: 0,339 $(N=2.999) . R^{2}$ ajustado3: 0,188 $(N=2.999)$.

O modelo proposto apresenta um bom ajustamento aos dados: $\chi^{2}(g l=80 ; N=2.999)=1448,045 p s<0,001 ; \chi^{2} /$ $g l=18,101 ; \mathrm{CFI}=0,951 ; \mathrm{AIC}=1558,045 ; \mathrm{PCFI}=0,634$ e RMSEA (IC 90\%) =0,076 (0,072-0,079).

A análise dos parâmetros estimados (Figura 1) indica que as variáveis motivo de poder e aprendizagem implicam atitude mais positiva em relação ao empreendedorismo e, dando seguimento ao processo, quanto mais positiva é a atitude, maior é a intenção dos estudantes em seguir a carreira empreendedora. A percepção de risco, por sua vez, funciona como um inibidor dessa intenção, uma vez que implica atitude menos positiva em relação ao empreendedorismo. Duas variáveis preditoras exercem efeitos diretos significativos, porém muito menores do que o efeito da atitude na intenção $\left(\beta_{\text {direto }}\right.$ Percepção de risco $\rightarrow$ intenção= $=0,02 ; \beta_{\text {direto }}$ Motivo de poder $\rightarrow$ intenção $=0,18 ; \beta_{\text {direto }}$ Aprendizagem empreendedora $\rightarrow$ intenção 0,06 ).

Para verificar a significância da mediação, os efeitos indiretos foram submetidos ao teste de Sobel (1982), seguindo os procedimentos propostos por Preacher e Hayes (2004). Os efeitos indiretos (mediados pela atitude) foram significativos para as três variáveis: percepção de risco $\left(\beta_{\text {indireto }}=-0,072 ; Z_{\text {sobel }}=-5,27 p s<0,001\right)$, motivo de $\operatorname{poder}\left(\beta_{\text {indireto }}=0,448 ; Z_{\text {sobel }}=19,449 p s<0,001\right)$ e aprendizagem empreendedora $\left(\beta_{\text {indireto }}=0,051 ; Z_{\text {sobel }}=3,581\right.$ $p s<0,001)$. Portanto, pode-se afirmar que a variável atitude medeia significativamente o efeito da percepção de risco, da aprendizagem e do motivo de poder na intenção empreendedora. Os efeitos totais foram todos significativos $(p s<0,001): \beta_{\text {total }}$ Percepção de risco $\rightarrow$ intenção=-0,089; $\beta_{\text {total }}$ Motivo de poder $\rightarrow$ intenção $=$ 0,$628 ; \beta_{\text {total }}$ Aprendizagem empreendedora $\rightarrow$ intenção $=0,110$. 


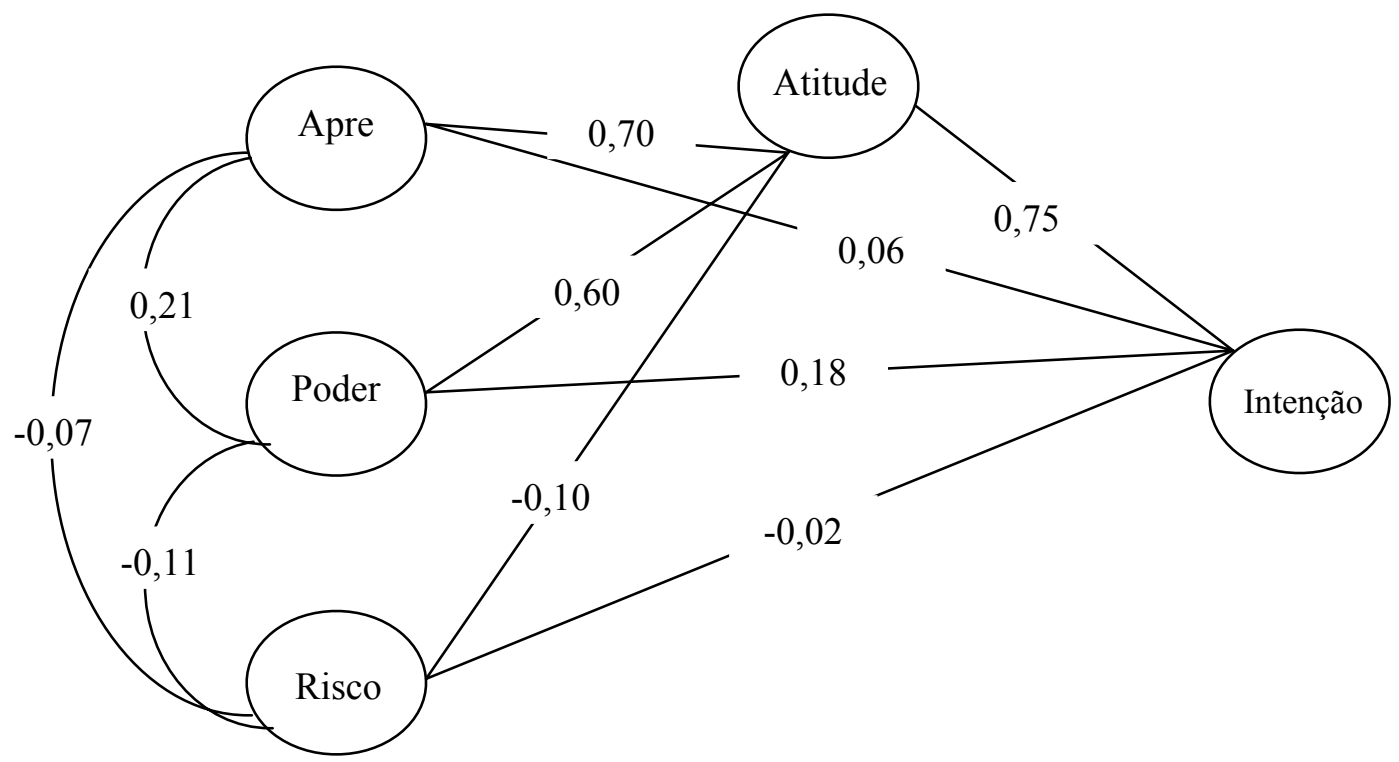

FIGURA 1. Modelo de mediação da atitude empreendedora na intenção empreendedora. ${ }^{* * *} p<0,001$. n.s. (risco-inten $\left.=-0,02\right)$. Atitu$\mathrm{de}=$ atitude empreendedora; Apre= aprendizagem empreendedora; Intenção=intenção empreendedora; Poder=motivação de poder; Risco=percepção de risco.

\section{DISCUSSÃO}

As variáveis preditoras e mediadoras do estudo estão associadas à intenção empreendedora (Tabela 2), fortalecendo a tese de que fatores individuais e da percepção de contexto ajudam a explicar a intenção empreendedora (p. ex., Gurol \& Atsan, 2006; Nascimento et al., 2010; Santos et al., 2009). Atitudes e percepção do controle percebido são as variáveis mais fortemente associadas à intenção, corroborando evidências empíricas encontradas a favor das teorias da ação refletida e da ação planejada na explicação da intenção empreendedora (p. ex., Ajzen, 1991; Ajzen \& Fishbein, 2005; Armitage \& Conner, 2001; Engle et al., 2010; Gelderen et al., 2008; Robinson et al., 1991; Schlaegel \& Koenig, 2014). Ao contrário dos estudos empíricos que sinalizam que a inclusão da percepção de controle ao lado das atitudes e das normas subjetivas aumenta o poder de explicação da intenção empreendedora (p. ex., Ajzen, 2011; Heidemann et al., 2011), isso não ocorreu neste estudo. A atitude positiva responde pela maior parte da explicação.

Motivações relacionadas à busca do poder (ter autoridade, ser meu próprio patrão, ter liberdade, tomar decisões e ser independente) estão mais associadas à intenção empreendedora que motivações ligadas à criatividade e à realização pessoal (trabalho desafiante e estimulante, criar algo novo), embora os dois grupos de motivações sejam significativos. Apesar de este estudo não explorar de modo direto a busca ativa por oportunidades, central para o empreendedorismo (Vaghely \& Julien, 2010), a mensuração de motivos de poder permite fazer inferências sobre orientação para o futuro, um indicador de perfil de busca de oportunidades (Kirzner, 1997; Schumpeter, 1949; Shane, 2012; Williams et al., 2009). Acumulam-se, então, novas evidências empíricas de que motivos econômicos e de realização pessoal encontram-se na base da escolha empreendedora (Fé de Pinho \& Gaspar, 2012). Adicionalmente, os dados sobre a motivação de poder oferecem suporte para um dos componentes do modelo de Krueger-Shapero (Krueger, 1993; Shapero \& Sokol,1982), ou seja, o forte desejo de se autoempregar.

Os resultados da percepção de contexto apontam que embora haja evidências de que variáveis contextuais explicam mais a intenção de escolha que variáveis individuais (p. ex., Vale et al., 2014; Wu \& Wu, 2008), a família parece não ter exercido influência para os universitários do estudo, contrariando alguns achados da literatura (p. ex, Almeida \& Teixeira, 2014). A aprendizagem empreendedora apresentou maior correlação com intenção empreendedora do que contato com disciplinas específicas de empreendedorismo. O mesmo pode ser dito em relação à percepção de um clima favorável e estimulante na universidade em prol do empreendedorismo. Nesta pesquisa, aprendizagem empreendedora se refere à percepção de que disciplinas cursadas contribuíram para o aperfeiçoamento de habilidades de gestão, para identificar oportunidades e criar redes de relação. Esse resultado fortalece evidência da importância das redes de colegas (incluindo competências sociais) e da 
identificação de oportunidades (incluindo a abertura à experiência) na intenção empreendedora (Abebe, 2012; Brandstätter, 2011; Correia-Santos et al., 2010; Kacperczyk, 2013; Kristiansen \& Indarti, 2004).

Análises de regressão sinalizam de modo claro que os melhores preditores de intenção empreendedora, sem incluir as atitudes, percepção de controle e normas subjetivas, são os motivos de poder e a aprendizagem empreendedora. A inclusão das três variáveis mediadoras na equação enfraquece a predição de ambas, a favor da atitude. Este resultado oferece evidência para a teoria da ação racional, mais que para a teoria da ação planejada, colocando em destaque que a disposição afetiva em relação ao empreendedorismo se mostrou mais relevante para estes estudantes universitários que a percepção de controle.

Análises das variáveis preditoras sobre as mediadoras ressaltam que a percepção de risco não parece impactar na atitude, mas afeta negativamente o controle percebido e em menor grau a norma subjetiva. Avaliar como altamente arriscado começar o próprio negócio e também administrá-lo implica perceber maiores riscos, o que parece impactar negativamente na intenção empreendedora. Evidência indireta de que a improvisação e o lidar com a incerteza constituem traços fundamentais do futuro empreendedor (Frese \& Gielnik, 2014). Embora a percepção de controle interno dos eventos seja importante, conforme vários estudos na literatura assim apontam, a aceitação do risco se torna uma condição igualmente relevante (p. ex., Pennings \& Wansink, 2004; Thomas \& Mueller, 2000), incluindo a abertura à experiência (p. ex., Brandstätter, 2011).

\section{Implicações teóricas}

O estudo oferece evidências a favor da teoria da ação planejada, mas ressalta também o papel fundamental da atitude na predição da intenção de escolha do empreendedorismo por universitários brasileiros, o que está mais em conformidade com a teoria da ação racional (refletida). Três componentes se encontram na base das atitudes: cognitivo (pensar), afetivo (sentir) e conativo (tendência a fazer) (Albarracin et al., 2005; Pereira, 2015).

Os resultados também apontam que a integração da teoria da ação racional e da teoria da ação planejada amplia a capacidade de explicação do fenômeno da intenção empreendedora. Ainda que a atitude positiva não assegure completamente a decisão de empreender, devendo ser levada em conta a percepção de controle pessoal sobre si e sobre o ambiente ao redor, somada ao contexto social mais imediato (foco da teoria da ação planejada), a atitude segue sendo o maior preditor, reafirmando o papel fundamental do engajamento afetivo sobre o comportamento-alvo.

O afeto sugere ter uma importância ainda maior ao se considerar o papel ambíguo da percepção de risco. Neste estudo, ela parece reduzir a atitude favorável ao empreendedorismo, impactando na intenção de ser empreendedor. No entanto, há modelos teóricos que destacam a importância de o empreendedor assumir riscos, o que está bastante relacionado à identificação de oportunidades (Krueger, 1993; Shapero \& Sokol, 1982). Ressalta-se, todavia, que a percepção de risco está fortemente carregada de afeto, inclusive afetos ambivalentes, o que exige maior necessidade de autorregulação emocional por parte do indivíduo. Assim, uma das implicações teóricas é a de que os modelos de explicação racional da intenção empreendedora necessitam incluir de modo mais visível os estados emocionais e processos regulatórios, que parecem estar fortemente envolvidos na tomada de decisão (p. ex., Grecucci \& Sanfey, 2014).

Se o empreendedorismo de fato contribui para o desenvolvimento econômico e social e acredita-se que a universidade seja um dos contextos de disseminação cultural, torna-se chave compreender de que modo se pode criar um clima afetivo, técnico e social que ofereça um ambiente mais favorável à tomada de decisões.

\section{Limitações e direções futuras}

Uma das limitações do estudo se deve à forma de medir o contexto universitário. Avaliar percepções de clima favorável ao empreendedorismo na universidade revela apenas uma disposição atitudinal para com a instituição formadora. Seria recomendável buscar indicadores objetivos que assegurem a variabilidade intraclasse e interclasse e que permitam o uso de análise multinível, visando explorar quais deles repercutem de fato na intenção empreendedora. Isso permitirá a construção de modelos de explicação mais integrados e sofisticados, alinhando-se aos esforços já em curso nessa direção (p. ex., Schlaegel \& Koenig, 2014). Ampliaria também o poder explicativo de variáveis de nível meso (p. ex., redes de relacionamento com colegas) e macro (política universitária de faculdades e centros de formação), e ajudaria a dar suporte a diretrizes universitárias para não só criar um ambiente mais favorável ao empreendedorismo, como também desenvolver competências 
que capacitem os jovens a lidar melhor com a incerteza de um futuro, principalmente em períodos de crise econômica como a que enfrenta o Brasil na atualidade.

\section{REFERÊNCIAS}

Abebe, M. A. (2012). Social and institutional predictors of entrepreneurial career intention: Evidence from hispanic adults in the U.S. Journal of Enterprising Culture, 20(1), 1-23. doi: 10.1142/S021849581250001X

Ajzen, I. (1985). From intentions to actions: A theory of planned behavior. In J. Kihl \& J. Beckmann (Orgs.), Action control: From cognition to behavior (pp. 11-39). Berlim: Springer-Verlag.

Ajzen, I. (1991). The theory of planned behavior. Organizational Behavior and Human Decision Processes, 50(2), $179-211$. doi:10.1016/0749-5978(91)90020-T

Ajzen, I. (2011). Behavioral interventions: Design and evaluation guided by the theory of planned behavior. In M. M Mark, S. I. Donaldson \& B. Campbel (Eds.), Social psychology and evaluation (pp. 72-100) New York: Guilford Press.

Ajzen, I., \& Fishbein, M. (2005). The influence of attitudes on behavior. In D. Albarracín, B. T. Johnson \& M. P. Zanna (Eds.), The handbook of attitudes (pp. 173-221). Mahwah: Lawrence Erlbaum.

Akmaliah, Z., Pihine, L., \& Bagheri, A. (2013). Self-efficacy and entrepreneurial intention. Vocations and Learning, 6(3), 385-401. doi:10.1007/s12186-013-9101-9

Albarracin, D., Johnson, B. T., Zanna, M., \& Kumkale, G. (2005). Attitude: Introduction and scope. In D. Albarracin, B.T. Johnson \& M. Zanna (Eds.), Handbook of attitudes (pp. 3-19). Mahwah: Lawrence Erbaum Associates.

Almeida, G. O. (2013). Valores, atitudes e intenção empreendedora: Um estudo com universitários brasileiros e cabo-verdianos (Tese de doutorado). Recuperado de http://bibliotecadigital.fgv.br/dspace/handle/10438/11281

Almeida, F. S., \& Teixeira, R. M. (2014). Influência da família e das redes sociais na criação de negócios por jovens empreendedores. Pretexto, 15(2), 110-128

Arbuckle, J. L. (2010). IBM SPSS Amos 19 user's guide. Chicago: IBM.

Armitage, C. J., \& Conner, M. (2001) Efficacy of the theory of planned behaviour: A meta-analytic review. British Journal of Social Psychology, 40(4), 471-499. doi: 10.1348/014466601164939

Bandura, A. (1991). Social cognitive theory of self-regulation. Organizational Behavior and Human Decision Processes, 50(2), 248-287. doi:10.1016/0749-5978(91)90022-L.

Bouckenooghe, D., Clercq, D. D., Willem, A., \& Buelens, M. (2007). An assessment of the validity in entrepreneurship research. Journal of Entrepreneurship, 16(2), 147-171. doi: 10.1177/097135570701600202

Brandstätter, H. (2011). Personality aspects of entrepreneurship: A look at five meta-analyses. Personality and Individual Differences, 51(3), 222-230. doi:10.1016/j.paid.2010.07.007

Byrne, B. (2001). Structural equation modeling with Amos: Basic concepts, applications and programming. New Jersey: Lawrence Erlbaum Associates.

Correia-Santos, S., Caetano, A., \& Curral, L. (2010). Atitude dos estudantes universitários face ao empreendedorismo: Como identificar o potencial empreendedor? Revista Portuguesa e Brasileira de Gestão, 9(4), 2-14.

Engle, R.L., Dimitriadi, N., Gavidia, J.V., Schlaegel, C., Delanoe, S., Alvarado, I., ... Wolff, B. (2010). Entrepreneurial intent: A twelve-country evaluation of Ajzen's model of planned behavior. International Journal of Entrepreneurial Behavior \& Research, 16(1), 35-57. doi: http://dx.doi.org/10.1108/13552551011020063

Fatoki, O. O. (2010). Graduate entrepreneurial intention in south africa: Motivations and obstacles. International Journal of Business and Management, 5(9), 87-98. doi: 10.5539/ijbm.v5n9p87

Fé de Pinho, L. M., \& Gaspar, F. A. C.(2012). Intenção empreendedora dos estudantes de ensino superior politécnico de Portugal (Relatório de pesquisa). Recuperado de http://repositorio.ipsantarem.pt/bitstream/10400.15/586/1/jornadas\%20LE\%20 UTAD.pdf

Fields, A. (2009). Descobrindo a estatística utilizando o SPSS. Porto Alegre: Artmed

Fini, R., Grimaldi, R., Marzzochi, G.L., \& Sobrero, M. (2009). The foundation of entrepreneurial intention. Recuperado de http:// www2.druid.dk/conferences/viewpaper.php?id=5955\&cf=32

Fishbein, M. (1963). An investigation of the relationships between beliefs about an object and the attitude toward that object. Human Relations, 16(3), 233-240. doi:10.1177/001872676301600302 
Fishbein, M., \& Ajzen, I. (1975). Belief, attitude, intention and behavior: An introduction to theory and research. Reading: AddisonWesley.

Franke, N., \& Luthje, C. (2004). Entrepreneurial intentions of business students: A benchmark study. International Journal of Innovation and Technology Management, 1(3), 269-288. doi: 10.1142/S0219877004000209

Franklin, R. J. (2013). Motives, self-regulation, and a re-conceptualization of entrepreneurial success. (Tese de doutorado). Recuperado de https://shareok.org/bitstream/handle/11244/11017/Franklin_okstate_0664D_12845.pdf?sequence=1

Frese, M., \& Gielnik, M.M. (2014). The psychology of entrepreneurship. Annual Review Organizational Psychology Organizational Behavior, 1, 413-1.438. doi: 10.1146/annurev-orgpsych-031413-091326

Gelderen, M. V., Brand, M., Praag, M.V., Bodewes, W., Poutsma, E., \& Gils, A. V. (2008). Explaining entrepreneurial intentions by means of the theory of planned behavior. Career Development International, 13(6), 538-559. doi: $10.1108 / 13620430810901688$

Geldhof, G. J., Weiner, M., Agans, J. P., Mueller, M. K., \& Lerner, R. M. (2014). Understanding entrepreneurial intent in late adolescence: The role of intentional self-regulation and innovation. Journal of Youth Adolescence, 43(1), 81-91. doi: $10.1007 / \mathrm{s} 10964-013-9930-8$

Gondim, S. M. G., \& Silva, N. (2013). Motivação no trabalho. In J. C. Zanelli, J. E. Borges-Andrade \& A. V. B. Bastos (Orgs.), Psicologia, organizações e trabalho no Brasil (2a ed., pp.173-202). Porto Alegre: Artmed.

Grecucci, A., \& Sanfey, A. G. (2014). Emotion regulation and decision making. In J. J. Gross (Ed.), Handbook of emotion regulation (2a ed., pp.140-155). New York: The Guilford Press.

Gurol, Y., \& Atsan, N. (2006). Entrepreneurial characteristics amongst university students: Some insights for entrepreneurship education and training in Turkey. Edutation \& Training, 48(1), 25-38. doi:10.1108/00400910610645716

Heidemann, L. A., Araujo, I. S., \& Veit, E. A. (2011). Um referencial teórico-metodológico para o desenvolvimento de pesquisas: A Teoria do Comportamento Planejado de Icek Ajzen. Revista Electrónica de Investigación em Educación em Ciências, $7(1), 1-10$.

Kacperczyk, A. J. (2013). Social influence and entrepreneurship: The effect of university peers on entrepreneurial entry. Organization Science, 24(3), 664-683. doi:10.1287/orsc.1120.0773

Kirzner, I. M. (1997). Entrepreneurial discovery and the competitive market process: An Austrian approach. Journal of Economic Literature, 35(1), 60-85.

Kristiansen, S., \& Indarti, N. (2004). Entrepreneurial intention among Indonesian and Norwegian students. Journal of Enterprising Culture, 12(1), 55-78. doi: 10.1142/S021849580400004

Krueger, N. F. (1993). The impact of prior entrepreneurial exposure on perceptions of new venture feasibility and desirability. Entrepreneurship Theory and Practice, 18(1), 5-21. doi: http://www.researchgate.net/publication/228314730

Liñán, F., \& Fayolle, A. (2015). A systematic literature review on entrepreneurial intentions: Citation, thematic analyses, and research agenda. International Entrepreneurship and Management Journal, 11(4), 907-933. doi 10.1007/s11365-015-0356-5

Liñán, F., Urbana, D., \& Guerrero, M. (2011). Regional variations in entrepreneurial cognitions: Start-up intentions of university students in Spain. Entrepreneurship \& Regional Development: An International Journal, 23(3-4), 187-215. doi:10.1080/08985620903233929

Marôco, J. (2010). Análise de equações estruturais: Fundamentos teóricos, software e aplicações. Portugal: Report Number.

Martin, M. A. G., \& Picazo, M. T. (2009). Entrepreneurship and economic policy objectives In M. V. Bradshaw \& P. T. Carrington (Eds.), Entrepreneurship and its economic significance (pp.193-204). New York: Nova Science Publishers.

Mortan, R.A., Ripoll, P., Carvalho, C., \& Bernal, M. C. (2014). Effects of emotional intelligence on entrepreneurial intention and self-efficacy. Journal of Work and Organizational Psychology, 30(3), 97-104. doi: http://dx.doi.org/10.1016/j.rpto.2014.11.004

Moutinho, K., \& Roazzi, A. (2010). As teorias da ação racional e da ação planejada: Relações entre intenções e comportamentos. Avaliação Psicológica, 9(2), 279-287.

Nanda, R., \& Sprensen, J. B. (2010). Workplace peers and entrepreneurship. Management Science, 56(7), 1116-1126. doi: $10.1287 / \mathrm{mnsc} .1100 .1179$

Nascimento, T. C., Dantas, A. B., Santos, P. C. F., Veras, M., \& Costa Jr., A. G. (2010). A metodologia de Kristiansen e Indarti para identificar intenção empreendedora em estudantes de ensino superior: comparando resultados obtidos na Noruega, Indonésia e Alagoas. Revista de Negócios, 15(3), 67-86.

Nishantha, B. (2009). Influence of personality traits and socio-demographic background of undergraduate students on motivation for entrepreneurial career: The Case of Sri Lanka. Dohisha Business School, 49(2), 71-82. 
Packham, G. Jones, P., Miller, C., Pickernell, D., \& Brychan, T. (2010). Attitudes towards entrepreneurship profiles of university students: A comparative analysis. Education + Training, 52(8/9), 568-586. doi:10.1108/00400911011088926

Parker, S.K., Bindl, U.K., \& Strauss, K. (2010). Making things happen: A model of proactive motivation. Journal of Management, 36(4), 827-856. doi: 10.1177/0149206310363732

Pennings, J. M. E., \& Wansink, B. (2004). Channel contract behavior: The role of risk attitudes, risk perceptions, and channel members' market structures. Journal of Business, 77(4), 697-723.

Pereira, M. E. (2015). Enfrentando preconceitos e esteretótipos: No trabalho, na escolas, nas ruas e os que sobrevivem em cada um de nós. Recuperado de http://estereotipos.net/enfrentando/apresent

Preacher, K. J., \& Hayes, A. F. (2004). SPSS and SAS procedures for estimating indirect effects in simple mediation models. Behavior Research Methods, Instruments, \& Computers, 36(4), 717-731.

Robinson, P., Stimpson, J., Heufner, H., \& Hunt, H. (1991). An attitude approach to the prediction of entrepreneurship. Entrepreneurship Theory and Practice, 15(4), 13-31.

Rocha, E. L. C., \& Freitas, A. A. F. (2014). Avaliação do ensino de empreendedorismo entre estudantes universitários por meio do perfil empreendedor. Revista de Administração Contemporânea, 18(4), 465-486. doi:10.1590/1982-7849rac20141512

Santos, P. C. F., Minuzzi, J., Lezana, A. G. R., \& Grzybovski, D. (2009). Intenção empreendedora: Um estudo com empretecos catarinenses. Revista de Estudos de Administração, 9(19), 7-26.

Shapero, A. (1984). The entrepreneurial event. In C. A. Kent (Ed.), The environment for entrepreneurship (pp.21-40). Lexington: Health.

Schlaegel, C., \& Koenig, M. (2014). Determinants of entrepreneurial intent: A meta-analytic test and integration of competing models. Entrepreneurship Theory and Practice, 38(2), 291-332. doi: 10.1111/etap.12087

Schoon, I., \& Duckworth, K. (2012). Who becomes an entrepreneur? Early life experiences as predictors of entrepreneurship. Developmental Psychology, 48(6), 1719-1726. doi: 10.1037/a0029168

Schumpeter, J. A. (1949). Economic theory and entrepreneurial history. In R. R. Wohl (Ed.), Change and the entrepreneur: Postulates and the patterns for entrepreneurial history. Cambridge: Harvard University Press.

Sesen, H., \& Pruett, M. (2014). The impact of education, economy, and culture on entrepreneurial motives, barriers and intention: A comparative study of the United States and Turkey. Journal of Entreprenuership, 23(2), 231-261. doi: $10.1177 / 0971355714535309$

Shane, S. (2012). Reflections on the 2010 AMR decade award: Delivering on the promise of entrepreneurship as a field of research. Academy of Management Review, 37(1), 10-20. doi: 10.5465/amr.2011.0078

Shapero, A., \& Sokol, L. (1982). Social dimensions of entrepreneurship. In C. A. Kent, D. L. Sexton, \& K. H. Vesper (Eds.), The encyclopedia of entrepreneurship (pp. 72-90). Englewood Cliffs: Prentice-Hall.

Shinnar, R., Pruett, M., \& Toney, B. (2009). Entrepreneurship education: Attitudes across campus. Journal of Education for Business, 84(30), 151-159. doi:10.3200/JOEB.84.3.151-159

Sivarajah, K., \& Achchuthan, S. (2013). Entrepreneurial Intention among Undergraduates: Review of Literature. European Journal of Business and Management, 5(5), 172-186.

Sobel, M. E. (1982). Asymptotic confidence intervals for indirect effects in structural equation models. Sociological Methodology, 13, 290-312. doi:10.2307/270723

Thomas, A. S., \& Mueller, S. L. (2000). A case for comparative entrepreneurship: Assessing the relevance of culture. Journal of International Business Studies, 31(2), 287- 301.doi: 10.1057/palgrave.jibs.8490906

Vaghely, I.P., \& Julien, P.A. (2010). Are opportunities recognized or constructed? An information perspective on entrepreneurial opportunity recognition. Journal of Business Venturing, 25(1). 73-86. doi:10.1016/j.jbusvent.2008.06.004

Vale, G. M. V. (2014) Empreendedor: Origens, concepções teóricas, dispersão e integração. Revista de Administração Contemporânea, 18(6), 874-891. doi: doi.org/10.1590/1982-7849rac20141244

Vale, G. M. V., Corrêa, V. S., \& Reis, R. F.(2014) Motivações para o empreendedorismo: Necessidade versus oportunidade? Revista de Administração Contemporânea, 18(3), 311-327. doi: doi.org/10.1590/1982-7849rac20141612

Williams, C. C., Round, D., Rodgers, P. (2009). Evaluating the motives of informal entrepreneurs: Some lessons from Ukraine. Journal of Developmental Entrepreneurship, 14(1), 59-71. doi: 10.1142/S1084946709001144

Wu, S., \& Wu, L. (2008). The impact of higher education on entrepreneurialintentions of university students in China. Journal of Small Business and Enterprise Development, 15(4), 752-774. doi: http://dx.doi.org/10.1108/14626000810917843 